\title{
Association among practice frequency on depression and stress among competitive US male wheelchair rugby athletes with tetraplegia
}

\author{
SL Silveira ${ }^{1}$, Ledoux $^{1}$, M Cottingham $^{1,2}$ and DC Hernandez ${ }^{1}$
}

\section{Study Design: Cross-sectional.}

Objectives: To determine whether frequency of training is related to self-reported lower psychological distress, defined as depressive symptomology and perceived stress, among the US male wheelchair rugby athletes with tetraplegia.

Setting: United States.

Methods: Survey data were collected on a convenience sample at wheelchair rugby tournaments from January-April 2016. Participants self-reported depressive symptomology (CES-D-10), perceived stress scale (PSS), and frequency of rugby practice. Covariate-adjusted regression models were conducted among the full sample and a subsample of individuals who reported spinal cord injury (SCl) as the nature of their disability.

Results: Participants included 150 males with tetraplegia, and 87\% identified the nature of their disability as SCI. Participants were primarily Caucasian with an average age of $\sim 35$ years. Participants scored low on measures of depressive symptomology (mean $=5.63$; s.d. $=4.35$ ) and perceived stress (mean $=4.63$; s.d. $=2.73$ ). Sixty-seven percent of the participants practiced two or more times per week. Results of the main analyses indicated that practicing wheelchair rugby two times or more (compared to once a week or less) was significantly associated with lower depressive symptomology and perceived stress among the full sample and subsample of individuals with SCl.

Conclusions: Greater frequency of wheelchair rugby participation was associated with lower levels of psychological distress. Future research should examine the directional and mechanistic relationship between frequency of sports participation and psychological distress to inform the benefits of adaptive sport.

Spinal Cord (2017) 55, 957-962; doi:10.1038/sc.2017.40; published online 16 May 2017

\section{INTRODUCTION}

Individuals with physical disabilities report higher levels of depression and psychological trauma and lower levels of life satisfaction ${ }^{1,2}$ than people without disabiltiies. Studies focused on populations with disabilities suggest that $\sim 50 \%$ experience clinically significant depressive symptoms ${ }^{3-6}$ compared to roughly $7 \%$ of people without disabiltiies. ${ }^{7}$ In addition, stress and depression show strong positive associations in disabled populations. ${ }^{8,9}$ Psychological distress is a general term often used in psychology that encompasses the emotional state experienced by individuals in response to a harmful stressor whether temporary or permanent including both depressive symptomology and stress. ${ }^{10}$ Understanding the factors related to reduced incidence of psychological distress in disabled individuals, such as sport participation, may have ultimately have implications for rehabilitation services.

In the United States today there are $\sim 276000$ people living with spinal cord injuries (SCI) with $\sim 80 \%$ of those individuals being men. ${ }^{11}$ Similar to the effects of sports participation among individuals without physical disabilities, ${ }^{12}$ participation in adaptive sports in general has a positive impact on psychological status. ${ }^{13-15}$ Physical activity, exercise and sport participation among individuals with
SCI have positive impacts on mental health, social relationships, employment status and community integration, all of which can enhance quality of life and independence in the performance of daily activities. ${ }^{16-20}$ Individuals with SCI who play sports at a higher level also exhibit markedly better psychological profiles. ${ }^{21,22}$

Further, time spent participating in sports may have an impact on psychological distress. In a study by Muraki et al. ${ }^{23}$ higher frequency of sports activity indicated lower scores of depression and trait anxiety among Japanese athletes with SCI across various sports. However, frequency of sport activity has not been investigated among a US sample, where access and availability to social services differs from Japan. While Muraki et al., ${ }^{23}$ focused on various sports activity, which provides the opportunity for a greater measure of frequency of physical activity, it does not pinpoint the effects of frequently participating in one sport, such as wheelchair rugby, which was designed for individuals with tetraplegia and primarily draws individuals with SCI. Understanding the effects of frequently participating in one sport is beneficial due to the monetary cost of participating in multiple adaptive sports. ${ }^{24}$

The current study aim is to gain a better understanding of the effect of sports participation on psychological distress indicators. To address

${ }^{1}$ Department of Health and Human Performance, University of Houston, Houston, TX, USA and ${ }^{2}$ Adaptive Athletics, University of Houston, Houston, TX, USA Correspondence: SL Silveira, Department of Health and Human Performance, University of Houston, 3875 Holman St Rm 104 Garrison, Houston, TX 77204, USA. E-mail: slsilvei@central.uh.edu

Received 2 September 2016; revised 26 March 2017; accepted 28 March 2017; published online 16 May 2017 
this aim, we examined the relationship between frequency of practicing wheelchair rugby on self-reported measures of depressive symptomology and perceived stress among US male wheelchair rugby athletes with tetraplegia when controlling for appropriate sociodemographic and injury-related factors. On the basis previous research, ${ }^{14,16,22,23}$ we hypothesized that athletes who engage in more frequent wheelchair rugby practice will score lower on self-report measures of depressive symptomology and perceived stress. The current study contributes to the literature by focusing on frequency of participating in one sport (wheelchair rugby) among a US sample. We build on the Muraki et al.,23 study, which did not include demographic and injury covariates that literature shows are correlated with frequency of practicing wheelchair rugby and depressive symptomology and stress. It is necessary to include these variables in regression models as the relationship between frequency of wheelchair rugby participation and psychological distress could be entirely accounted for by the influences of the demographic and injury variables. A significant negative association between practice frequency and psychological distress measures could have implications for designing future studies on sport participation and psychological distress among populations with tetraplegia.

\section{MATERIALS AND METHODS}

\section{Participants}

The Health among Athletes with Disabilities study was designed to examine the psychosocial health of wheelchair rugby athletes. Participants included a sample of adult male wheelchair rugby athletes from across the United States. The approximate number of athletes participating in wheelchair rugby at time of data collection on a team roster in the United States Quad Rugby Association was 600. This sample included a range of athletes from national level competitors to individuals playing for less than 6 months at developmental tournaments. Inclusion criteria included men 18 years or older, identify as having tetraplegia, and involvement in a competitive wheelchair rugby league as part of a team. On the basis of personal communication with the President of the International Wheelchair Rugby Federation (IWRF) only 36 women are currently on the roster of all the US teams, which averages about one woman per team (R Lujano, personal communication, 4 April 2015); the authors believe this is a unique population that needs to be studied separately. Participants were involved in tournaments from January-April 2016. Participants were recruited during recreation time and between games. Informed consent was obtained from all participants prior to completing questionnaires. The study was approved by the University of Houston (omitted for review)'s Institutional Review Board.

\section{Measures \\ Depression. Self-report depressive symptomology was measured using 10 -items from the Center for Epidemiological Studies Depression Scale (CES-D-10). ${ }^{25}$ The CES-D-10 has been found to be reliable and valid among individuals with SCI. ${ }^{25}$ Responses to each item range from $0=$ Rarely or none of the time (less than 1 day) to $3=$ All of the time (5-7 days), with a possible total range of $0-30$. Items are summed and higher scores indicate the presence of greater symptomatology. When using the CES-D-10, a cutoff score of 10 has been used in previous literature ${ }^{25,26}$ to recommend further assessment for clinical depressive symptomology.}

Perceived stress. The perceived stress scale (PSS) is a four-item self-rating scale designed to assess the degree to which respondents perceive their lives to be stressful in the past month. ${ }^{27}$ (For example, 'In the last month, how often have you felt that you were unable to control the important things in your life?'). Items are rated on a five-point scale from $0=$ never to $4=$ very often, and total scores may range from 0 to 16 . Higher scores indicate greater perceived stress. The Cronbach's alpha for the PSS in this sample was .66. Similar to previous published studies focused on vulnerable populations, this scale was modified to assess perceived stress over the past week. ${ }^{28}$
Frequency practicing wheelchair rugby. Frequency practicing rugby was measured using a multiple choice question, 'How often do you practice rugby while in season?' Answer choices included: less than once a month, once a month, once a week, two times a week and more than 2 times a week. Answer choices were dichotomized to 'once a week or less' versus 'two or more times a week' based on prior work in sports participation research and evidence of the benefits of engaging in exercise training two times per week in adults with SCI. ${ }^{29,30}$

Demographic characteristics were collected regarding age (years), race (white vs minority), education (less than an associate's degree vs associates degree or more), employment (employed vs unemployed), marital status (married/cohabitating vs single), household income ( $\$ 74999$ vs $\geqslant \$ 75000$ ), number of adults residing in household, time post injury (years), SCI status (not a spinal cord injury vs spinal cord injury), participation in sports before injury (no vs yes), and IWRF functional classification (low functioning $0.5-1.5$ vs high functioning 2.0-3.5). ${ }^{31}$ The IWRF classification is a point-based measure of muscle and functional ability of athletes; higher values indicate higher functioning. All IWRF classifiers are trained in a certified protocol. ${ }^{31}$

\section{Procedure}

All athletes attending wheelchair rugby events were given the option to complete a survey that included items regarding demographics, rugby involvement and psychosocial information. Trained research assistants administered all questionnaires at tournament locations. Paper and pencil questionnaires were used for the data collection. Participants were seated in a quiet area and asked to answer all questions to the best of their ability and understanding on their own or with a research assistant helping with written responses. Average total time to complete the full survey was $20 \mathrm{~min}$, survey included other measures as part of a larger study outside the scope of this research question.

\section{Statistics}

All analyses were performed using IBM SPSS Statistics for Windows, Version 22 (SPSS Inc., IBM Corp., Armonk, NY, USA, 2013). Data were tested for skewness and met all assumptions. The primary independent variable of interest was frequency of rugby practice and primary dependent variables of interest self-report CES-D-10 depression score and PSS perceived stress score. To test hypotheses, linear regressions were used to test the association between (a) frequency of practice and depressive symptomatology and (b) frequency of practice and perceived stress; each adjusted for age, race, education, employment, marital status, household income, number of adults in the household, time post injury, SCI status, and IWRF functional classification. Because of the etiology of disability, individuals with SCI often vary from individuals with other disabilities, specifically congenital disabilities, on measure of psychological distress and adjustment. ${ }^{21}$ For that reason two additional separate linear regression analyses were conducted on a subsample of individuals who reported SCI as the nature of their disability $(n=130)$.

\section{RESULTS}

\section{Sample characteristics}

Participants included 150 men with tetraplegia. Participants were 34.7 (s.d. = 8.56) years old on average (Table 1). On average, participants experienced the injury that caused tetraplegia 15.57 (s.d. $=10.76)$ years prior $($ median $=12.46)$ (range 0.25-64.66), and $\sim 87 \%$ of the participants identified the nature of their disability as a SCI. The other injuries causing disability included cerebral palsy, cancer and amputations (data not shown).

Participants scored low on the depression measure with an average score of 5.63 (s.d. $=4.35$ ) with a range of 0-22 (Table 1). Further analyses indicated that $17 \%$ of the sample scored 10 or higher (data not shown), indicating further assessment for depressive symptomology. Participants also scored low on the perceived stress scale with an average score of 4.63 (s.d. $=2.73$ ) and a range of $0-13$. 
Table 1 Description of the sample $(N=150)$

\begin{tabular}{|c|c|}
\hline & Mean (s.d.) or \% \\
\hline \multicolumn{2}{|l|}{ Dependent variables } \\
\hline \multicolumn{2}{|l|}{ Psychological distress } \\
\hline Depressive symptomology & $5.6(4.35)$ \\
\hline Perceived stress & $4.6(2.73)$ \\
\hline \multicolumn{2}{|l|}{ Independent variable } \\
\hline \multicolumn{2}{|l|}{ Frequency of practicing wheelchair rugby } \\
\hline Once a week or less & 33 \\
\hline Two times or more & 67 \\
\hline \multicolumn{2}{|l|}{ Demographic and injury characteristics } \\
\hline Age & $35(8.56)$ \\
\hline \multicolumn{2}{|l|}{ Race } \\
\hline White & 82 \\
\hline Minority & 18 \\
\hline \multicolumn{2}{|l|}{ Education } \\
\hline Less than an associate's degree & 37 \\
\hline Associates degree or more & 63 \\
\hline \multicolumn{2}{|l|}{ Employment } \\
\hline Employed & 55 \\
\hline Unemployed & 45 \\
\hline \multicolumn{2}{|l|}{ Marital status } \\
\hline Married/cohabitating & 27 \\
\hline Single & 73 \\
\hline \multicolumn{2}{|l|}{ Household Income } \\
\hline$\leqslant \$ 74999$ & 57 \\
\hline$\geqslant \$ 75000$ & 43 \\
\hline Number of adults that reside in the household & $2(0.97)$ \\
\hline Time post injury (years) & $16(10.76)$ \\
\hline \multicolumn{2}{|l|}{ Spinal cord injury } \\
\hline No & 13 \\
\hline Yes & 87 \\
\hline \multicolumn{2}{|l|}{ IWRF functional classification } \\
\hline Low functioning $(0.5-1.5)$ & 49 \\
\hline High functioning (2.0-3.5) & 51 \\
\hline
\end{tabular}

Abbreviation: IWRF, International Wheelchair Rugby Federation.

Further, $67 \%$ of the athletes were participating in wheelchair rugby practice two or more times per week.

Table 2 indicates that athletes participating in rugby two or more times per week scored significantly lower on self-reported depressive symptomology $($ mean $=5.17 ;$ s.d. $=4.03)$ compared to athletes practicing once a week or less $($ mean $=6.54 ;$ s.d. $=4.83 ; P<0.10)$. In addition, athletes participating in rugby two or more times per week scored significantly lower on self-reported perceived stress $(4.19$; s.d. $=2.59)$ compared to athletes practicing once a week or less (mean $=5.50 ;$ s.d. $=2.81 ; P<0.01)$.

Results of the main analyses indicated that practicing wheelchair rugby two times or more (compared to once a week or less) was significantly associated with self-reported depressive symptomology $(\beta=-1.80$, confidence interval $(\mathrm{CI})=-3.37$ to $0.23, P<0.05)$ (Table 3). Therefore, depressive symptomology scores for individuals participating in rugby two or more times per week were on average 1.8 points lower. These estimates are associated with uncertainty as reflected in the 95\% CI. Income was negatively associated with lower self-reported depressive symptomology scores, in which those with an income over $\$ 75000$ scored significantly lower. Practicing wheelchair rugby two times or more (compared to once a week or less) was
Table 2 Average psychological distress by frequency of practicing wheelchair rugby, mean (s.d.)

\begin{tabular}{|c|c|c|}
\hline & \multicolumn{2}{|c|}{ Psychological distress } \\
\hline & Depressive symptomology & Perceived stress \\
\hline \multicolumn{3}{|c|}{ Frequency of practicing wheelchair rugby } \\
\hline Once a week or less $(n=50)$ & $6.54(4.83)$ & $5.50(2.81)$ \\
\hline Two times or more $(n=100)$ & $5.17(4.03)^{\mathrm{a}}$ & $4.19(2.59)^{b}$ \\
\hline
\end{tabular}

bSignificantly different from 'once a week or less' at $P<0.01$.

significantly related to lower levels of self-reported perceived stress $(\beta=-1.69, \mathrm{CI}=-2.6$ to $-0.72, P<0.001)$ in adjusted analyses. That is, perceived stress scores for individuals participating in rugby two or more times per week were on average 1.7 points lower. These estimates are associated with uncertainty as reflected in the 95\% CI. Several covariates were marginally associated with perceived stress. For example, having an associate's degree or more and income over $\$ 75000$ were both related to lower self-reported perceived stress. Higher functional status (that is, IWRF classification of 2.0-3.5) was associated with higher self-reported perceived stress. Associations between frequency of practicing wheelchair rugby and self-reported depressive symptomology $(\beta=-1.69, \mathrm{CI}=-3.39$ to $0.21, P<0.10)$ and perceived stress $(\beta=-1.77, \mathrm{CI}=-2.8$ to $-0.74, \quad P<0.001)$ were consistent in subsample of 130 athletes with SCI as their nature of disability (Table 4).

\section{DISCUSSION}

Building on Muraki et al., ${ }^{23}$ the purpose of this study is to gain a better understanding of the effect of sports participation on psychosocial indicators of health in US males with tetraplegia. Results supported the hypothesis that athletes who engage in more frequent practice score lower on measures of psychological distress when controlling for appropriate sociodemographic and injury-related factors. Psychological distress is extremely common after SCI, with $\sim 50 \%$ of the population with SCI reporting clinically significant symptomology. ${ }^{5,6}$ However, among the current study sample findings indicate that scores for depressive symptomology were lower than the overall population with SCI with only $17 \%$ of participants scoring over the clinically significant cutoff of 10. Scores of self-report perceived stress were slightly higher than non-disabled populations. Normative sample scores for perceived stress in the non-disabled population are 4.49 (s.d.=4.96), and our sample reported average scores $4.63\left(\right.$ s.d. = 2.73). ${ }^{32}$ Although the literature has shown individuals with disabilities typically report high levels of psychological distress, the scores in the current sample of men with tetraplegia were slightly higher but relatively comparable to the non-disabled general population.

Athletes who practiced wheelchair rugby two or more times per week scored significantly lower on measures of both self-reported depressive symptomology and perceived stress. This is a contribution to the literature indicating that time involved in sport may impact psychological status and should be further examined longitudinally. This study is the first to use practice frequency in wheelchair rugby in a multivariate regression model predicting psychological distress. The results for the full sample and subsample of individuals with SCI indicated that practicing wheelchair rugby two or more times per week was associated with lower measures of self-reported psychological distress. Previous work in this area has focused primarily on sports participation or non-participation as well as differences 
Table 3 OLS regression models predicting depressive symptomology and perceive stress as a factor of frequency practicing wheelchair rugby, full sample $(N=150)$

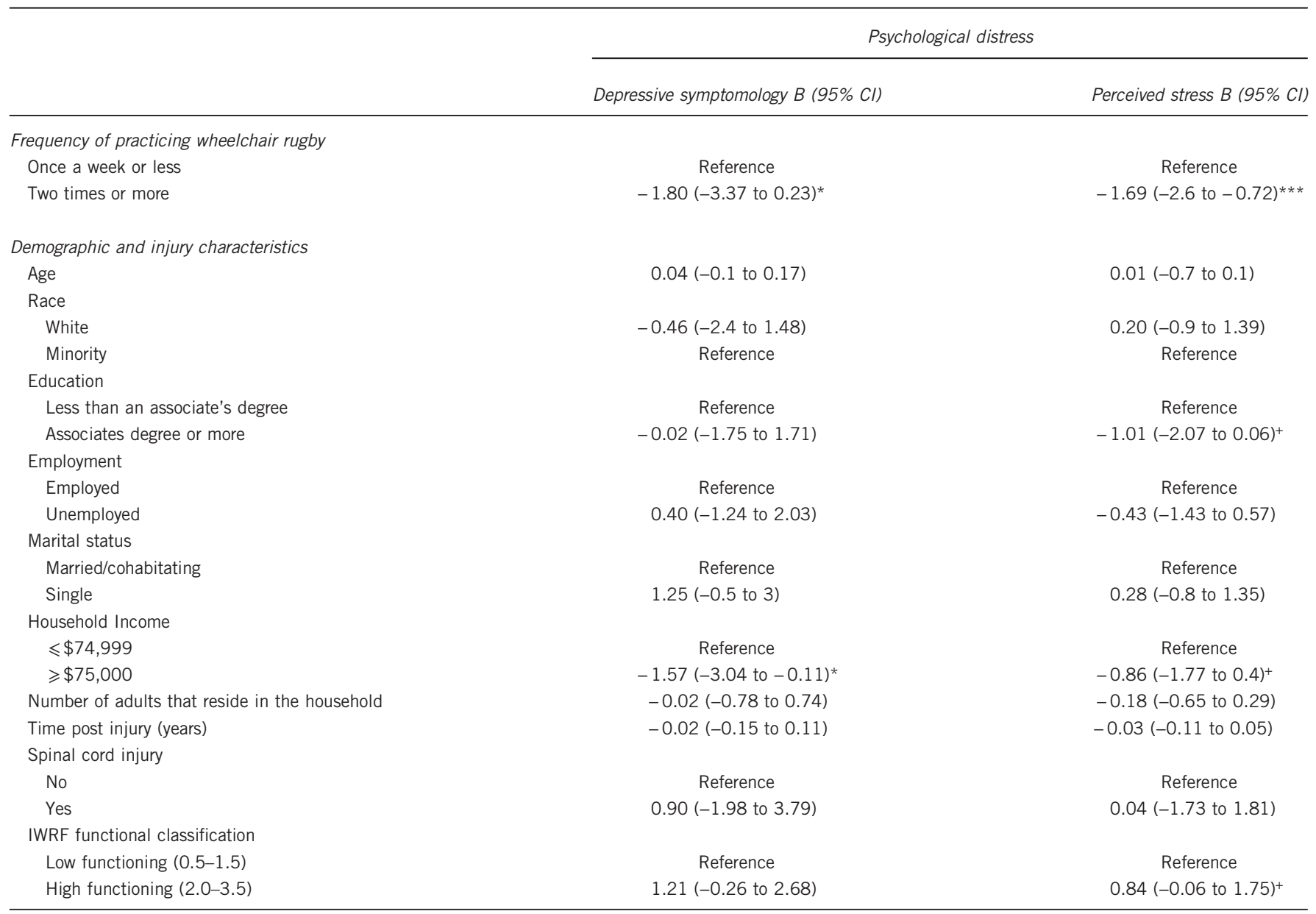

Abbreviations: $\mathrm{Cl}$, confidence interval; IWRF, International Wheelchair Rugby Federation.

${ }^{*} P<0.05 ;{ }^{* * *} P<0.001 ;{ }^{+} P<0.10$.

between sports and specific exercise protocols. ${ }^{13-15,29,33,34}$ Results provide a new perspective exploring the frequency of sport participation and psychological distress, which may inform researchers and practitioners on factors related to positive mental health status in individuals with tetraplegia.

The cross-sectional nature of the data does not provide us the opportunity to assess the directionality of the relationship between frequency of practicing wheelchair rugby and self-reported measures of psychological distress among individuals with tetraplegia, but it does appear that these factors may be contributing to lower psychological distress scores in this sample compared to a general disabled population..$^{35,36}$ The positive association may be derived from social support from teammates, ${ }^{37}$ and improved functional ability and general health status. $29,33,34$ Specifically, previous work shows distinct themes in wheelchair rugby player experiences including 'it is okay to be a quad, do not tell us we cannot and the power of wheelchair rugby,' which may influence feelings of community membership, self-confidence, fulfillment of needs, and provide emotional connections. ${ }^{37}$ Future work is needed to better understand which aspects of frequently being involved in a team sport may be contributing to psychological status, including the direction of this relationship and key mechanisms (for example, physical activity versus social support).
Higher levels of education and household income were related to lower psychological distress scores in this sample. This sample was educated (associates or greater: 63\%) and moderately affluent (\$75 000 or higher: 43\%). More educated individuals may have greater resources, which provides them the opportunity to obtain mental health assistance. On the other hand, wheelchair rugby participation may have assisted individuals in engaging in education and community opportunities, contributing to lower psychological distress.

Further, participating in multiple adaptive sports is generally not feasible for many individuals with tetraplegia because purchasing and maintaining the necessary sport-related equipment is costly. ${ }^{24}$ Results suggest wheelchair rugby may be a viable option to maintain a healthy mental status for individuals who are able to only participate in one sport following SCI. The relatively low frequency (two or more times) is also a benefit for those who have barriers to accessing equipment and/or facilities to play the sport.

In addition to the limitations stated above, this study is based on a convenience sample and lacks a control group or randomization to groups. Results for psychological distress scores are compared to previous research in general population with SCI and other disabilities. However, a controlled research study of the current population with SCI would widen the scope of our understanding of the impact 
Table 4 OLS regression models predicting depressive symptomology and perceive stress as a factor of frequency practicing wheelchair rugby, spinal cord injury subsample $(N=130)$

\begin{tabular}{|c|c|c|}
\hline & \multicolumn{2}{|c|}{ Psychological distress } \\
\hline & Depressive symptomology B $(95 \% \mathrm{Cl})$ & Perceived stress B $(95 \% \mathrm{Cl})$ \\
\hline \multicolumn{3}{|l|}{ Frequency of practicing wheelchair rugby } \\
\hline Once a week or less & Reference & Reference \\
\hline Two times or more & $-1.69(-3.39 \text { to } 0.21)^{+}$ & $-1.77(-2.8 \text { to }-0.74)^{* * *}$ \\
\hline \multicolumn{3}{|l|}{ Demographic and injury characteristics } \\
\hline Age & $0.09(-0.06$ to 0.25$)$ & $0.07(-0.02$ to 0.17$)$ \\
\hline \multicolumn{3}{|l|}{ Race } \\
\hline White & $-0.23(-2.38$ to 1.97$)$ & $0.24(-1.09$ to 1.54$)$ \\
\hline Minority & Reference & Reference \\
\hline \multicolumn{3}{|l|}{ Education } \\
\hline Less than an associate's degree & Reference & Reference \\
\hline Associates degree or more & $-0.70(-2.55$ to 1.29$)$ & $-1.50(-2.68 \text { to }-0.36)^{*}$ \\
\hline \multicolumn{3}{|l|}{ Employment } \\
\hline Employed & Reference & Reference \\
\hline Unemployed & $-0.19(-1.93$ to 1.68$)$ & $-1.06(-2.16 \text { to } 0.02)^{+}$ \\
\hline \multicolumn{3}{|l|}{ Marital status } \\
\hline Married/cohabitating & Reference & Reference \\
\hline Single & $1.63(-0.25 \text { to } 3.53)^{+}$ & $0.48(-0.67$ to 1.62$)$ \\
\hline \multicolumn{3}{|l|}{ Household income } \\
\hline$\leqslant \$ 74999$ & Reference & Reference \\
\hline$\geqslant \$ 75000$ & $-1.94(-3.53 \text { to }-0.39)^{*}$ & $-1.19(-2.13 \text { to } 0.23)^{*}$ \\
\hline Number of adults that reside in the household & $0.13(-0.76$ to 0.98$)$ & $0.21(0.3$ to 0.74$)$ \\
\hline Time post injury (years) & $-0.01(-0.17$ to 0.14$)$ & $-0.06(-0.15$ to 0.04$)$ \\
\hline \multicolumn{3}{|l|}{ IWRF functional classification } \\
\hline Low functioning $(0.5-1.5)$ & Reference & Reference \\
\hline High functioning (2.0-3.5) & $1.32(-0.44$ to 2.92$)$ & $1.06(-0.1 \text { to } 2.01)^{*}$ \\
\hline
\end{tabular}

Abbreviations: $\mathrm{Cl}$, confidence interval; IWRF, International Wheelchair Rugby Federation.

${ }^{*} P<0.05 ;{ }^{* * *} P<0.001 ;{ }^{+} P<0.10$

of frequent sport participation on mental health following a SCI. Further, state-dependent psychological variables related to engaging in competitive activity such as team comradery and game outcomes may have impacted the participants' motivation to complete survey data or influenced their survey responses. It is possible that individuals with better psychological status are more likely to train in sport more often; control of confounding variables is not possible and causal inferences cannot be determined due to the cross-sectional, self-report nature of this study. Additionally, a measure of psychological treatment was not included and would be beneficial in future studies as a potential confounder. Despite the limitations, the findings contribute to a scant literature base on the health status of wheelchair rugby athletes, which could aid in designing future research studies among populations with tetraplegia, which could ultimately influence rehabilitation outcomes.

\section{CONCLUSIONS}

Overall, scores on indicators of psychological distress were low and participation in wheelchair rugby two or more times a week was associated with better psychological status in adult males with tetraplegia. The next step in research is to understand the directional and mechanistic relationship between frequency of sport participation and psychological distress in order to identify how and if sport impacts mental health status following SCI. This type of research could eventually benefit and increase rehabilitation outcomes and quality of life in individuals with tetraplegia.

\section{CONFLICT OF INTEREST}

The authors declare no conflict of interest.

\section{ACKNOWLEDGEMENTS}

We thank undergraduate research assistants from the Department of Health and Human Performance and Adaptive Athletics for their assistance in data collection. We also thank all the athletes who participated in the study for their contribution would have not made this study possible. Funding for this project was support by TIRR Memorial Hermann to Drs MC and DCH through University of Houston's Adaptive Athletics.

1 Fuhrer MJ, Rintala DH, Hart KA, Clearman R, Young ME. Depressive symptomatology in persons with spinal cord injury who reside in the community. Arch Phys Med Rehabil 1993; 74: 255-260.

2 Kemp BJ, Krause JS. Depression and life satisfaction among people ageing with post-polio and spinal cord injury. Disabil Rehabil 1999; 21: 241-249.

3 Frank RG, Kashani JH, Wonderlich SA, Lising A, Visot LR. Depression and adrenal function in spinal cord injury. Am J Psychiatry 1985; 142: 252-253.

4 Fullerton DT, Harvey RF, Klein MH, Howell T. Psychiatric disorders in patients with spinal cord injuries. Arch Gen Psychiatry 1981; 38: 1369-1371.

5 Krause JS, Kemp B, Coker J. Depression after spinal cord injury: relation to gender, ethnicity, aging, and socioeconomic indicators. Arch Phys Med Rehabil 2000; 81: 1099-1109.

6 Schönherr M, Groothoff J, Mulder G, Eisma W. Participation and satisfaction after spinal cord injury: results of a vocational and leisure outcome study. Spinal Cord 2005; 43: 241-248.

7 National Institute of Mental Health (NIMH). Depression. Available at: http://www.nimh. nih.gov/health/topics/depression/index.shtml (2016).

8 Gerhart KA, Weitzenkamp DA, Kennedy P, Glass CA, Charlifue SW. Correlates of stress in long-term spinal cord injury. Spinal Cord 1999; 37: 183-190. 
9 Rintala DH, Loubser PG, Castro J, Hart KA, Fuhrer MJ. Chronic pain in a communitybased sample of men with spinal cord injury: prevalence, severity, and relationship with impairment, disability, handicap, and subjective well-being. Arch Phys Med Rehabil 1998; 79: 604-614.

10 Ridner SH. Psychological distress: concept analysis. J Adv Nurs 2004; 45: 536-545.

11 National Spinal Cord Injury Statistical Center (NSCISC). Annual Statistical Report. Available at: https://www.nscisc.uab.edu/PublicDocuments/reports/pdf/2015\%20NSCISC \%20Annual\%20Statistical\%20Report\%20Complete\%20Public\%20Version.pdf (accessed February 2015).

12 Babiss LA, Gangwisch JE. Sports participation as a protective factor against depression and suicidal ideation in adolescents as mediated by self-esteem and social support. J Dev Behav Pediatr 2009; 30: 376-384.

13 Greenwood CM, Dzewaltowski DA, French R. Self-efficacy and psychological well-being of wheelchair tennis participants and wheelchair nontennis participants. Adapt Phys Activ Q 1990; 7: 12-21.

14 McVeigh SA, Hitzig SL, Craven BC. Influence of sport participation on community integration and quality of life: a comparison between sport participants and non-sport participants with spinal cord injury. J Spinal Cord Med 2009; 32: 115.

15 Paulsen $\mathrm{P}$, French R, Sherrill C. Comparison of wheelchair athletes and nonathletes on selected mood states. Percept Mot Skills 1990; 71: 1160-1162.

16 Gioia MC, Cerasa A, Di Lucente L, Brunelli S, Castellano V, Traballesi M. Psychological impact of sports activity in spinal cord injury patients. Scand J Med Sci Sports 2006; 16: 412-416.

17 Kawanishi CY, Greguol M. Physical activity, quality of life, and functional autonomy of adults with spinal cord injuries. Adapt Phys Activ Q 2013; 30: 317-337.

18 Lastuka A, Cottingham M. The effect of adaptive sports on employment among people with disabilities. Disabil Rehabil 2015; 38: 1-7.

19 Martin Ginis KA, Jorgensen S, Stapleton J. Exercise and sport for persons with spinal cord injury. Pm r 2012; 4: 894-900.

20 Tasiemski T, Brewer BW. Athletic identity, sport participation, and psychological adjustment in people with spinal cord injury. Adapt Phys Activ Q 2011; 28: 233-250.

21 Campbell E. Psychological well-being of participants in wheelchair sports: comparison of individuals with congenital and acquired disabilities. Percept Mot Skills 1995; 81: 563-568.

22 Kljajić D, Eminović F, Dopsaj M, Pavlović D, Arsić S, Otašević J. The impact of sports activities on quality of life of persons with a spinal cord injury. Zdr Varst 2016; 55: 94-101.
23 Muraki S, Tsunawake N, Hiramatsu S, Yamasaki M. The effect of frequency and mode of sports activity on the psychological status in tetraplegics and paraplegics. Spinal Cord 2000; 38: 309-314.

24 Rimmer JH, Riley B, Wang E, Rauworth A, Jurkowski J. Physical activity participation among persons with disabilities: barriers and facilitators. Am J Prev Med 2004; 26 : 419-425.

25 Miller WC, Anton HA, Townson AF. Measurement properties of the CESD scale among individuals with spinal cord injury. Spinal Cord 2008; 46: 287-292.

26 Andresen EM, Malmgren JA, Carter WB, Patrick DL. Screening for depression in well older adults: evaluation of a short form of the CES-D (Center for Epidemiologic Studies Depression Scale). Am J Prev Med 1994; 10: 77-84.

27 Cohen S, Kamarck T, Mermelstein R. A global measure of perceived stress. $J$ Health Soc Behav 1983; 24: 385-396.

28 Okamoto H, Fisher FD, Hernandez DC, Reitzel LR, Kendzor DE, Kish DH et al. Trait mindfulness and stress among homeless adults. Health Behav Policy Rev 2015; 2: 122-129.

29 Hicks AL, Martin KA, Ditor DS, Latimer AE, Craven C, Bugaresti J et al. Long-term exercise training in persons with spinal cord injury: effects on strength, arm ergometry performance and psychological well-being. Spinal Cord 2003; 41: 34-43.

30 Wu SK, Williams T. Factors influencing sport participation among athletes with spinal cord injury. Med Sci Sports Exerc 2001; 33: 177-182.

31 Gumbert W. BlazeSport Wheelchair Rugby Manual. BlazeSport Clubs of America: Atlanta, GA, USA, 2004

32 Cohen S, Williamson GM. Perceived stress in a probability sample of the United States. In: Spacapan S, Oskamp S (eds). The social psychology of health: Claremont Symposium on Applied Social Psychology. Sage: Newbury Park, CA, USA, 1988, 31-67.

33 Curtis KA, McClanahan S, Hall KM, Dillon D, Brown KF. Health, vocational, and functional status in spinal cord injured athletes and nonathletes. Arch Phys Med Rehabil 1986; 67: 862-865.

34 Dallmeijer AJ, Hopman MT, van As $\mathrm{HH}$, van der Woude LH. Physical capacity and physical strain in persons with tetraplegia; the role of sport activity. Spinal Cord 1996; 34: 729-735.

35 Tasiemski T, Bergstrom E, Savic G, Gardner BP. Sports, recreation and employment following spinal cord injury-a pilot study. Spinal Cord 2000; 38: 173-184.

36 Trenaman L, Miller WC, Queree M, Escorpizo R. Modifiable and non-modifiable factors associated with employment outcomes following spinal cord injury: A systematic review. J Spinal Cord Med 2015; 38: 422-431.

37 Goodwin D, Johnston K, Gustafson P, Elliott M, Thurmeier R, Kuttai H. Its okay to be a quad: wheelchair rugby players sense of community. Phys Activ Q 2009; 26: 102-117. 